\title{
Assessment of growth and metabolism characteristics in offspring of dehydroepiandrosterone-induced polycystic ovary syndrome adults
}

\author{
Ying Huang ${ }^{1,2,3, *}$, Jiang-Man Gao ${ }^{1,3, *}$, Chun-Mei Zhang ${ }^{1,2}$, Hong-Cui Zhao ${ }^{1,3}$, Yue Zhao ${ }^{1,2}$, \\ Rong $\mathrm{Li}^{1,3}$, Yang $\mathrm{Yu}^{1,2,3}$ and Jie Qiao ${ }^{1,2,3}$ \\ ${ }^{1}$ Reproductive Medical Center, Department of Obstetrics and Gynecology, Peking University Third Hospital, \\ Beijing, China, ${ }^{2}$ Key Laboratory of Assisted Reproduction, Ministry of Education, Beijing, China and \\ ${ }^{3}$ Beijing Key Laboratory of Reproductive Endocrinology and Assisted Reproductive Technology, Beijing, China \\ Correspondence should be addressed to Y Yu or R Li or Y Zhao; Email: yuyang5012@hotmail.com or roseli001@sina.com or \\ zhaoyue0630@163.com
}

*(Y Huang and J-M Gao contributed equally to this work)

\begin{abstract}
Polycystic ovary syndrome (PCOS) is a common reproductive disorder that has many characteristic features including hyperandrogenemia, insulin resistance and obesity, which may have significant implications for pregnancy outcomes and long-term health of women. Daughters born to PCOS mothers constitute a high-risk group for metabolic and reproductive derangements, but no report has described potential growth and metabolic risk factors for such female offspring. Hence, we used a mouse model of dehydroepiandrosterone (DHEA)-induced PCOS to study the mechanisms underlying the pathology of PCOS by investigating the growth, developmental characteristics, metabolic indexes and expression profiles of key genes of offspring born to the models. We found that the average litter size was significantly smaller in the DHEA group, and female offspring had sustained higher body weight, increased body fat and triglyceride content in serum and liver; they also exhibited decreased energy expenditure, oxygen consumption and impaired glucose tolerance. Genes related to glucolipid metabolism such as Ppary, Acot1/2, Fgf21, Pdk4 and Inhbb were upregulated in the liver of the offspring in DHEA group compared with those in controls, whereas Cyp17a1 expression was significantly decreased. However, the expression of these genes was not detected in male offspring. Our results show that female offspring in DHEA group exhibit perturbed growth and glucolipid metabolism that were not observed in male offspring.

Reproduction (2016) 152 705-714
\end{abstract}

\section{Introduction}

Polycystic ovary syndrome (PCOS) is a common reproductive disorder with many characteristics, including hyperandrogenemia, insulin resistance and obesity, which may have significant implications for pregnancy outcomes and long-term health of women. Familial history of PCOS represents a risk factor for development of the disorder, as first-degree relatives of patients with PCOS have higher prevalence of PCOS (Legro et al. 1998, Kahsar-Miller et al. 2001). Familial aggregation of PCOS kindreds suggests the involvement of a major genetic component(s) in this disorder. However, the results of subsequent genetic studies have been inconsistent and cannot fully explain the pathogenesis of PCOS.

PCOS women have increased risk of prenatal and neonatal complications such as gestational diabetes, pregnancy-induced hypertension, pre-eclampsia and preterm birth (Boomsma et al. 2006). Also, infants of women with PCOS are more likely to be large or small for gestational age (Sir-Petermann et al. 2005, Anderson et al. 2010). In a two-period study, female infants and prepubertal girls born to PCOS mothers were found to have significantly higher levels of antiMullerian hormone (AMH), whereas the concentrations of gonadotropin and sex steroids in both PCOS groups were comparable with those of control groups (Sir-Petermann et al. 2006). The observed higher levels of $\mathrm{AMH}$ in PCOS daughters were found to continue into adolescence (Crisosto et al. 2007). AMH is produced by granulosa cells and reflects follicular development. As such, the increase in AMH suggests that daughters of PCOS women may have altered follicular development during infancy and childhood (Crisosto et al. 2007).

Prepubertal and pubertal daughters of PCOS women have a normal body mass index and Tanner stage distribution but have some hormonal perturbations 
and differences in metabolic parameters (Sir-Petermann et al. 2007). Hyperinsulinemia and an increased ovarian volume occur with PCOS before the onset of puberty and persist during pubertal development (Sir-Petermann et al. 2009). Considering the early onset and the nature of the metabolic and sex hormone alterations, PCOS daughters constitute a high-risk group for metabolic and reproductive derangements (Sir-Petermann et al. 2007, 2009). Owing to the complexity of the multiple factors that induce PCOS, a comprehensive evaluation of PCOS offspring has not been reported. Studies of PCOS offspring have been conducted only with small sample sizes and included a single ethnic group (Crisosto et al. 2007, Sir-Petermann et al. 2007). The follow-up period only reached adolescence-a period of rapid change and hormonal fluctuations-and thus is not representative of hormone metabolism or cannot completely represent the hormone metabolism situation in adulthood.

Androgen excess is the most common defect underlying PCOS, and it manifests in $25-60 \%$ of patients. PCOS patients have elevated levels of adrenal androgens, particularly dehydroepiandrosterone (DHEA), its sulfoconjugate and androstenedione (Carmina et al. 1992, Moran et al. 1999). Phenotypic and metabolic variations among PCOS patients lead to substantial variation in results.

In this study, we investigated the growth and metabolic indices of offspring conceived from DHEAinduced PCOS mice to illuminate their developmental characteristics and determine the expression profiles of key genes. Our results provide a fundamental basis for comprehending potential health issues affecting PCOS offspring.

\section{Materials and methods}

All chemicals used in this study were purchased from SigmaAldrich Chemical Company unless otherwise stated.

\section{Ethics approval}

All procedures involving mice were carried out following strict criteria of the Guide for Care and Use of Laboratory Animals of Peking University, and the protocol was approved by the Institutional Animal Care and Use Committee of Peking University Third Hospital.

\section{PCOS-like model}

Female prepubertal (25-days old) mice of the BALB/C strain (Vital River Laboratories, Beijing, China) were randomly divided into the DHEA group and control group. The PCOSlike mouse model was established by subcutaneously injecting DHEA $(6 \mathrm{mg} / 100 \mathrm{~g}$ body weight dissolved in $0.05 \mathrm{~mL}$ sesame oil) once daily for 20 consecutive days as described (Huang et al. 2015). All mice were raised and housed in the Animal Center of the Medical College of Peking University according to the national legislation for animal care. All mice were maintained under controlled temperature and lighting conditions and allowed free access to food and water. After 20 days of treatment, eight to ten mice per group were killed for model validation (Huang et al. 2015).

\section{Offspring acquisition}

Mice from both control and DHEA groups were superovulated via intraperitoneal injection of $10 \mathrm{IU}$ of equine chronic gonadotropin (Hua Fu Biotechnology, Tianjin, China), followed by $10 \mathrm{IU}$ of human chorionic gonadotropin (HCG, Hua Fu Biotechnology) $48 \mathrm{~h}$ later. On the same day, equine chronic gonadotropin was given, DHEA administration was stopped. DHEA and control mice were paired with BALB/c males (6-8 weeks of age) in the evening of HCG injection, and the females with confirmed vaginal plugs the next morning were considered pregnant. Spontaneous delivery was allowed, and offspring were weaned at age 3 weeks. Female and male offspring were fed separately until age 12 weeks and weighed weekly. All offspring were maintained under controlled temperature and lighting conditions and allowed free access to food and water. Metabolic status and reproductive function were assessed at age 12-13 weeks, with the exception of estrous cycle evaluation, which was performed at age 6 weeks.

\section{Body composition analysis}

To determine body fat mass composition, offspring were placed in a clear plastic holder without anesthesia or sedation and inserted into an EchoMRI device (Echo Medical Systems, Houston, TX, USA) at age 12-13 weeks. Eight female and eight male mice were assessed per group.

\section{Indirect calorimetry}

Energy expenditure was measured using an indirect opencircuit calorimeter (Oxylet; Panlab, Spain). Mice were placed individually into metabolic cages for $48 \mathrm{~h}$. After a 24-h acclimation period, oxygen consumption $\left(\mathrm{VO}_{2}\right)$ and carbon dioxide production $\left(\mathrm{VCO}_{2}\right)$ were monitored for 3 min every hour in each cage for $24 \mathrm{~h}$. At the same time, locomotor activity was monitored by Activity Sensor (Oxylet), and these data were collected every $2 \mathrm{~min}$. Energy expenditure (in $\left.\mathrm{kcal} / \mathrm{day} / \mathrm{kg}^{0.75}=[3.815+1.232 \times \mathrm{RQ}] \times \mathrm{VO}_{2} \times 1.44\right)$ and respiratory quotient $\left(\mathrm{RQ}=\mathrm{VCO}_{2} / \mathrm{VO}_{2}\right)$ were calculated using METABOLISM software (Oxylet). Eight female and eight male mice per group were assessed at age 12-13 weeks.

\section{Blood pressure measurement}

The blood pressure of offspring (eight mice per group) was measured with a CODA noninvasive blood pressure meter (Kent Scientific, Torrington, CT, USA) at age 12-13 weeks.

\section{Oral glucose tolerance test}

An oral glucose tolerance test was performed in mice following an $8 \mathrm{~h}$ fast. Glucose levels were measured in 
tail-vein blood samples using a blood glucose meter (Sinocare, Changsha, China). After the fast, glucose levels were measured, and then glucose $(2 \mathrm{~g} / \mathrm{kg}$ body weight dissolved in $10 \mathrm{~mL}$ water) was administered to mice by oral gavage, and tail-vein samples were obtained at 30, 60, 90 and 120 min after administration.

\section{Blood sampling for insulin, leptin and lipid profiles and measurement of hepatic cholesterol and triglycerides}

At age 12-13 weeks, eight female and male offspring in each group were killed. Blood was drawn from the inner canthus after the mice were fasted for $8 \mathrm{~h}$. The serum was immediately separated and stored at $-80^{\circ} \mathrm{C}$ for subsequent analysis or hormone determinations. Leptin and fasting insulin levels were measured with radioimmunoassay kits (Beijing North Institute of Biological Technology, Beijing, China). Lipid profiles were determined using biochemical analysis kits (China Diagnostics Medical Corporation, Beijing, China). After blood sample collection, each liver was immediately removed and stored at $-80^{\circ} \mathrm{C}$. Total cholesterol $(\mathrm{CHO})$ and triglycerides (TG) were extracted from liver and measured with a Tissue Total Cholesterol Assay Kit and Tissue Triglyceride Assay Kit (Applygen Technologies, Beijing, China).

\section{Quantitative real-time PCR}

Quantitative real-time PCR was used to determine the levels of the expression of glucolipid metabolism-related genes in liver. Total RNA from the liver was isolated with TRIzol reagent (Invitrogen). cDNA was synthesized using the First Strand cDNA Synthesis kit (Thermo Fisher). For quantitative PCR, amplification was performed with an ABI7500 (Applied Biosystems) using the SYBR Green kit (Applied Biosystems). The cycling conditions were $2 \mathrm{~min}$ at $95^{\circ} \mathrm{C}$, followed by 40 cycles of $30 \mathrm{~s}$ at $95^{\circ} \mathrm{C}$ and $1 \mathrm{~min}$ at $60^{\circ} \mathrm{C}$ for annealing. GAPDH served as the internal control for gene expression normalization. The relative expression levels of the glucolipid metabolism-related genes were calculated using the $2^{-\Delta \Delta C T}$ method. All primers were synthesized by Sangon Company, and the sequences are shown in Supplementary Table 1, see section on supplementary data given at the end of this article.

\section{Statistical analysis}

Measurement data were presented as the mean \pm S.E.M. Statistical significance was determined as indicated by two independent sample $t$-tests, Mann-Whitney $U$ test and $\chi^{2}$ tests, using SPSS 16.0 software appropriately. A $P$ value of $<0.05$ was considered to reflect a statistically significant difference.

\section{Results}

\section{Producing offspring by superovulating DHEA-induced PCOS female mice}

DHEA-induced PCOS female mice and control female mice were mated with normal BALB/C male mice (a single male mouse per female). The pregnancy rate in the DHEA group was only $8 \%$ (compared with $67 \%$ for the control group), which was too low to obtain sufficient offspring; hence, in subsequent experiments, hormone therapy was used to stimulate ovulation.

In the control group, a vaginal plug was observed in 10 mice after stimulating ovulation and mating, and 7 mice produced offspring (70\%); average litter size was $7.6 \pm 1.0$. In the DHEA group, a vaginal plug was observed in 13 mice, and 6 mice produced offspring (46\%); average litter size was $4.2 \pm 2.3$, which was significantly smaller than that of the control group $(P<0.05)$.

\section{Growth index comparison between offspring of DHEA and control mice}

As shown in Fig. 1A, the average body weight of female offspring of DHEA mice was significantly greater than that of the control group from one week after birth until adulthood (12 weeks). During postnatal weeks 1-4, the body weight of male offspring in the DHEA group also was significantly greater than that of male offspring in the control group. However, no difference in male offspring body weight was observed between the two groups from postnatal weeks 5-12 (Fig. 1B).
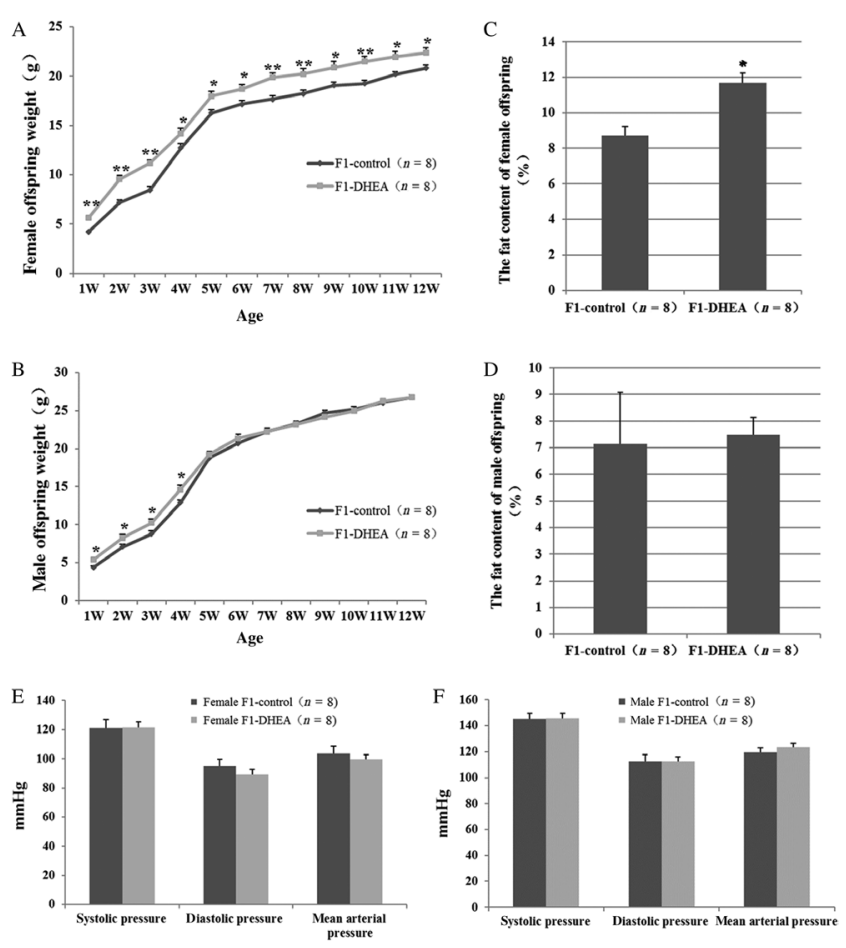

Figure 1 Growth of offspring of DHEA and control mice. (A and B) Growth curves for female offspring (A) and male offspring (B) during postnatal weeks 1-12. (C and D) Fat content of female offspring (C) and male offspring (D) at age 12 weeks. (E and F) Systolic, diastolic and mean arterial pressure of female (E) and male (F) offspring. Values are the mean \pm S.E.M., and $\mathrm{n}$ denotes the number of mice. ${ }^{*} P<0.05$, $* * P<0.01$ vs control group. 

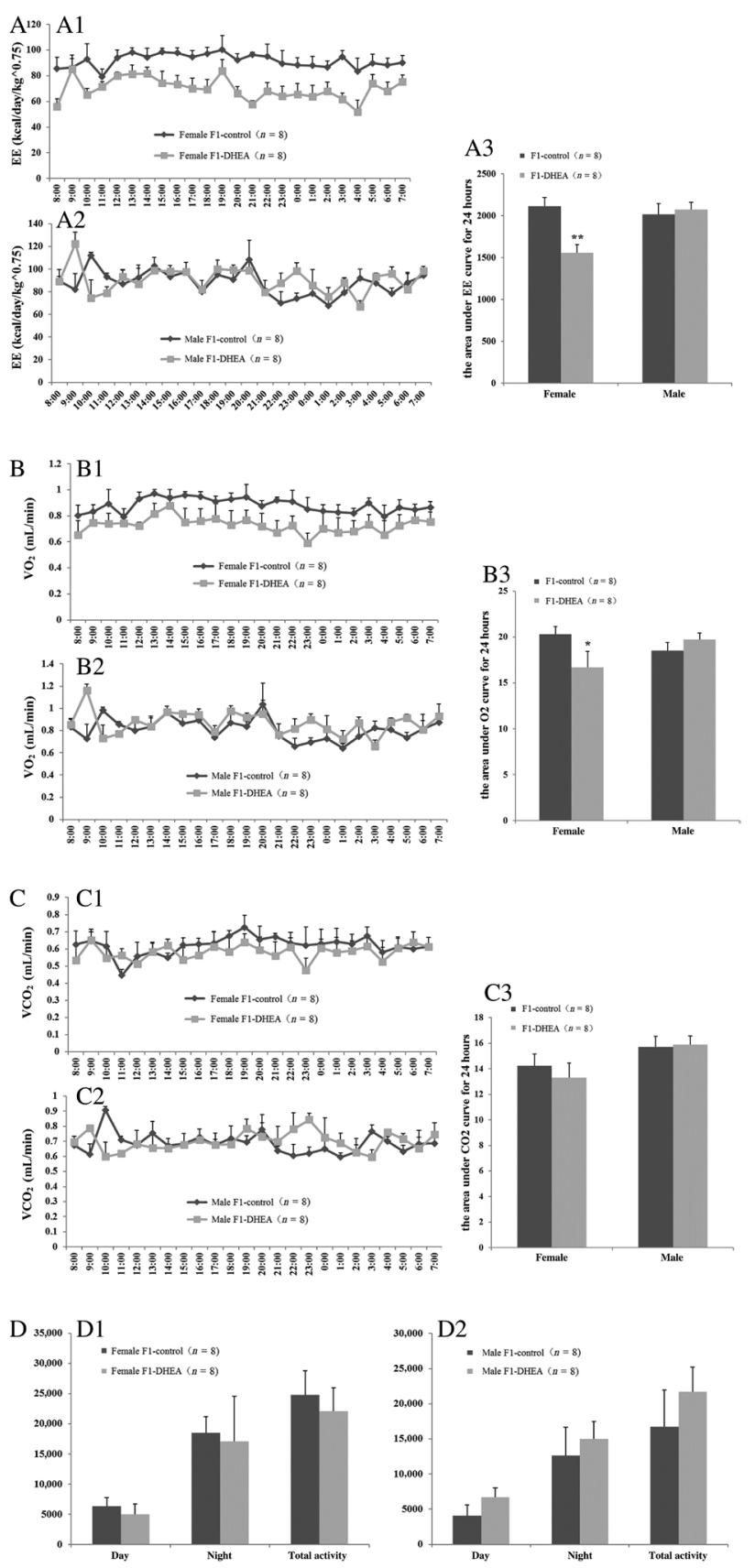

Figure 2 Metabolism level in offspring of DHEA and control mice. (A) Energy consumption: A1, female offspring, dynamic change of energy consumption in 24-h; A2, male offspring, dynamic change of energy consumption in 24-h; A3, area under the curve (AUC) for energy consumption in 24 hours in female and male offspring. (B) Oxygen consumption: $\mathrm{B} 1$, female offspring, dynamic change of $\mathrm{O}_{2}$ consumption in 24-h; B2, male offspring, dynamic change of $\mathrm{O}_{2}$ consumption in 24-h; B3, AUC for $\mathrm{O}_{2}$ consumption in $24 \mathrm{~h}$ in female and male offspring. (C) $\mathrm{CO}_{2}$ production: $\mathrm{C} 1$, female offspring, dynamic change of $\mathrm{CO}_{2}$ production in $24 \mathrm{~h}$; $\mathrm{C} 2$, male offspring, dynamic change of $\mathrm{CO}_{2}$ production in $24 \mathrm{~h}$. $\mathrm{C} 3, \mathrm{AUC}$ for $\mathrm{CO}_{2}$ production in $24 \mathrm{~h}$ in female and male offspring; (D) Activity: D1, female offspring, activity during the day, night and over a 24-h period; D2, male offspring activity during the day, night and over a $24-\mathrm{h}$ period. ' $n$ ' denotes the number of mice. $* P<0.05,{ }^{* *} P<0.01$ vs control group.
Fat mass of the offspring at age 12 weeks was measured by magnetic resonance imaging. The mean fat mass percentage for female offspring was $11.69 \pm 0.55 \%$ in the DHEA group and $8.71 \pm 0.52 \%$ in the control group, a difference that was statistically significant (Fig. 1C). The mean fat mass of male offspring did not differ significantly between the two groups $(7.48 \pm 0.66 \%$ vs $7.15 \pm 1.92 \%$ respectively, Fig. $1 \mathrm{D})$.

As metabolic disorders often leads to vascular endothelial dysfunction and increased risk of hypertension, blood pressure was measured in adult offspring. For both female and male offspring, there were no significant differences in systolic, diastolic or mean arterial pressure between the DHEA and control groups (Fig. 1E and F).

\section{Comparison of metabolic level between offspring of DHEA and control mice}

Obesity is often caused by excessive food intake or metabolic changes, resulting in weight gain and pathological changes induced by excess body fat accumulation. Energy consumption and activity levels can indirectly reflect the metabolic levels and provide an explanation for weight change. In this study, dynamic changes in energy consumption (energy expenditure), $\mathrm{VO}_{2}, \mathrm{VCO}_{2}$ and activity were monitored with a respiratory metabolism detector for $24 \mathrm{~h}$ for eight female and eight male offspring from each group.
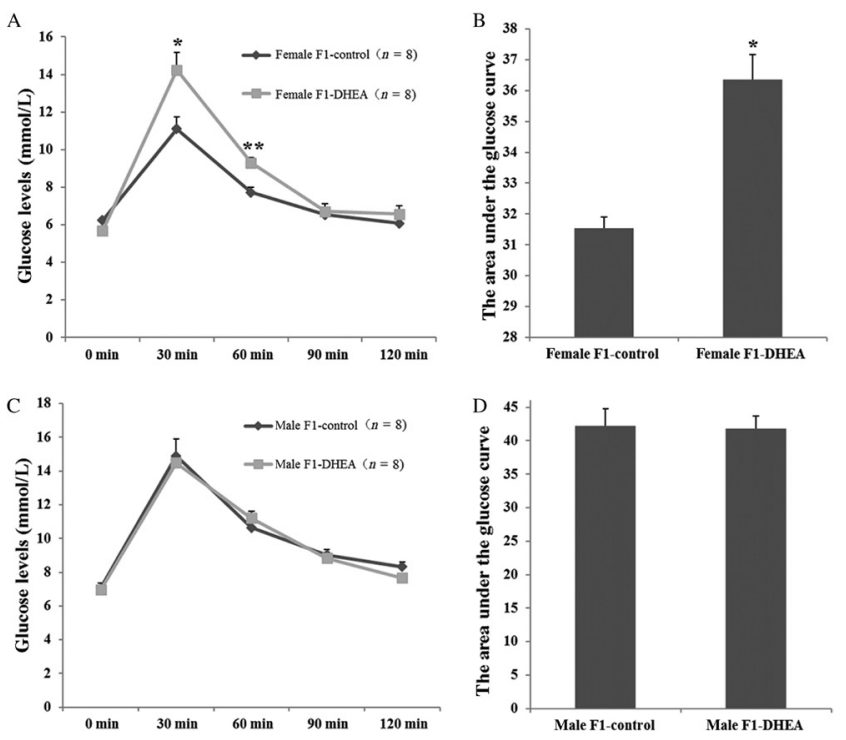

Figure 3 Oral glucose tolerance test (OGTT) for offspring of DHEA and control mice. (A) Blood glucose level curves for female offspring at each time point. (B) OGTT area under the curve for female offspring. (C) Blood glucose level curves for male offspring at each time point. (D) OGTT area under the curve for male offspring. ' $n$ ' denotes the number of mice. ${ }^{*} P<0.05,{ }^{* *} P<0.01$ vs control group. 
Table 1 Lipid and insulin level in offspring of DHEA and control mice.

\begin{tabular}{lcccc}
\hline & Female F1-control $(n=8)$ & Female F1-DHEA $(n=8)$ & Male F1-control $(n=8)$ & Male F1-DHEA $(n=8)$ \\
\hline Total $\mathrm{CHO}(\mathrm{mmol} / \mathrm{L})$ & $1.63 \pm 0.12$ & $1.53 \pm 0.14$ & $2.40 \pm 0.13$ & $2.19 \pm 0.19$ \\
TG $(\mathrm{mmol} / \mathrm{L})$ & $0.95 \pm 0.05$ & $2.21 \pm 0.35 *$ & $1.08 \pm 0.12$ & $1.34 \pm 0.13$ \\
$\mathrm{HDL}(\mathrm{mmol} / \mathrm{L})$ & $1.29 \pm 0.10$ & $1.26 \pm 0.12$ & $1.82 \pm 0.08$ & $1.75 \pm 0.16$ \\
LDL $(\mathrm{mmol} / \mathrm{L})$ & $0.19 \pm 0.01$ & $0.18 \pm 0.01$ & $0.23 \pm 0.02$ & $0.22 \pm 0.01$ \\
FBG $(\mathrm{mmol} / \mathrm{L})$ & $5.10 \pm 0.41$ & $4.40 \pm 0.20$ & $6.52 \pm 0.39$ & $6.58 \pm 0.22$ \\
FINS $(\mu \mathrm{lU} / \mathrm{mL})$ & $10.31 \pm 0.65$ & $11.07 \pm 0.79$ & $14.34 \pm 0.85$ & $14.58 \pm 1.20$ \\
$\mathrm{HOMA}-\mathrm{IR}$ & $2.55 \pm 0.23$ & $2.18 \pm 0.22$ & $4.16 \pm 0.37$ & $4.30 \pm 0.44$ \\
Leptin $(\mathrm{ng} / \mathrm{mL})$ & $7.94 \pm 0.20$ & $7.06 \pm 0.88$ & $5.55 \pm 0.69$ & $5.04 \pm 0.27$ \\
\hline
\end{tabular}

$* P<0.05$, vs control group.

Data for energy expenditure were adjusted for body weight. Female offspring of DHEA mothers showed sustained lower levels of energy consumption and $\mathrm{VO}_{2}$ (Fig. 2A and B). No difference was observed for male offspring. Moreover, $\mathrm{VCO}_{2}$ and physical activity did not differ significantly in female/male offspring of DHEA and control mice at any time over the 24-h period (Fig. 2C and D).

An oral glucose tolerance test was performed to assess insulin sensitivity in adult offspring. In female offspring, the glucose level at both 30 and 60 min after the sugarwater lavage was significantly higher in the DHEA group than that in the control group. Moreover, the area under the curve for glucose was also significantly greater, suggesting impaired glucose tolerance in DHEA female offspring. However, compared with control males, the glucose tolerance of the male offspring was unaffected, with comparable blood glucose levels at each time point (Fig. 3).

Fasting serum lipids and metabolism-related hormone levels in offspring were measured in 12-week-old mice. Except for serum TG level, which was significantly higher in the DHEA female offspring, other indicators, such as HOMA-IR, cholesterol, HDL, LDL, insulin and leptin levels, did not differ significantly between the two groups (Table 1 ).

The liver is the central hub of human metabolism, regulating both glucose and lipid metabolism. We thus measured $\mathrm{CHO}$ and TG levels in the liver. Mean liver TG concentration was $1108.7 \pm 183.4 \mu \mathrm{mol} / \mathrm{g}$ in the DHEA female offspring, which was significantly greater than that of female controls $(455.8 \pm 82.32 \mu \mathrm{mol} / \mathrm{g})$; total $\mathrm{CHO}$, however, was similar in the two groups
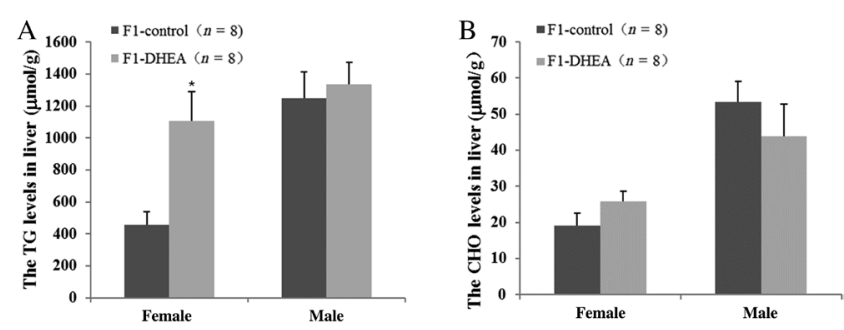

Figure $4 \mathrm{TG}$ and $\mathrm{CHO}$ content of liver and muscle tissue in offspring of DHEA and control mice. (A) TG content in liver tissue. (B) Total $\mathrm{CHO}$ content in liver tissue. ' $n$ ' denotes the number of mice. ${ }^{*} P<0.05$ vs control group.
(Fig. 4A and B). For the male offspring, there was no difference in liver TG or $\mathrm{CHO}$ levels between the two groups (Fig. 4A and B).

\section{Expression of genes that regulate glucolipid metabolism in liver tissue}

To determine the potential molecular mechanism underlying the observed dynamic metabolic changes in PCOS female mice, we used real-time PCR to assess the expression of 36 glucolipid metabolism-related genes in liver tissue of female offspring of DHEA and control mothers (three cases per group). Among these genes, 17 were associated with lipid synthesis, transport and metabolism (Acc, Acs, CD36, Cpt-2, Cyp17a1, Fas, Fatp, Fgf2 1, Hmgcl, Hmgcs2, Inhbb, Lepr, Ppara, Pparß, Ppary, Scd and Vnn 1; Smith 2002, Lee et al. 2003, Yoon 2009, Rakhshandehroo et al. 2010, Nakamura et al. 2014), 6 were associated with glucose synthesis and metabolism (Aqp3, Glut4, Gyk, Pck1, Pdk4 and Pepck; Lee et al. 2003, Yoon 2009, Nakamura et al. 2014) and
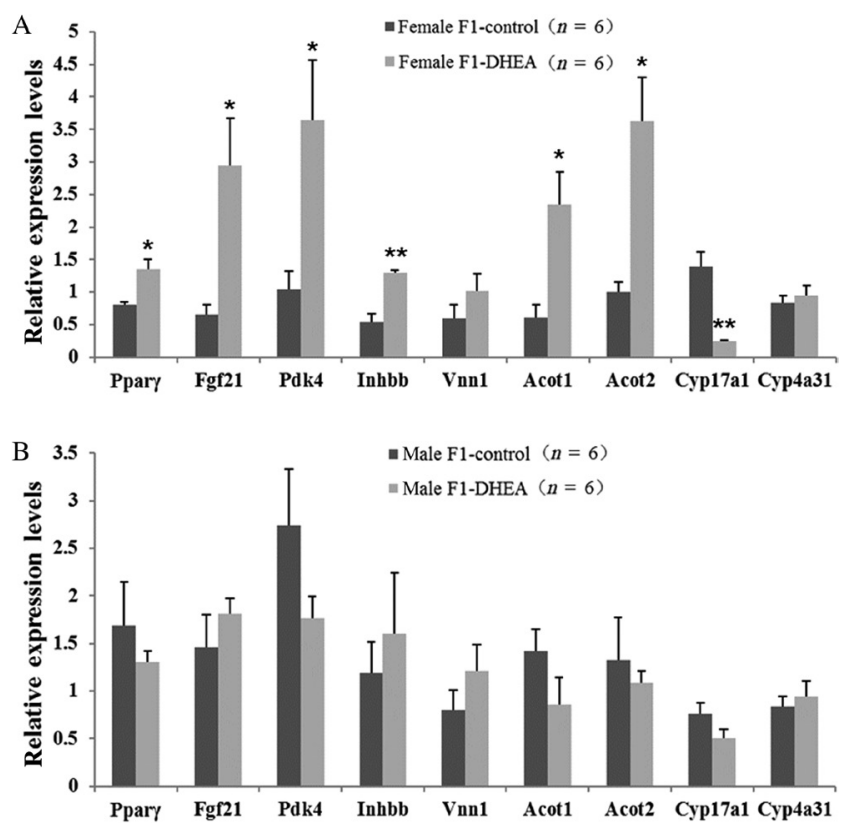

Figure 5 Real-time PCR assay of differential expression genes in liver of offspring. (A) Female offspring. (B) Male offspring. ' $n$ ' denotes the number of mice. ${ }^{*} P<0.05,{ }^{* *} P<0.01$ vs control group. 
13 were associated with oxidation and decomposition (Acaa1a, Acot1, Acot2, Acox1, Aldh3a1, Cpt1A, Cyp4a1, Cyp4a31, Etfdh, Hadha, Hsd17b4, Ucp2 and Ucp3; Lee et al. 2003, Yoon 2009, Nakamura et al. 2014). Preliminary screening results showed that, for the female offspring, 9 genes (Acot1, Acot2, Cyp4a31, Cyp17a1, Fgf21, Inhbb, Pdk4, Ppary and Vnn1) were expressed differently between the DHEA and control groups. To verify the expression of these 9 genes in the liver of female and male offspring, the sample size was expanded to six mice per group. As assessed by mRNA level, the expression of each of Ppary, Fgf21, Pdk4, Inhbb, Acot 1 and Acot 2 was significantly upregulated in DHEA female offspring, whereas Cyp17a1 was significantly downregulated (Fig. 5A). Unlike in female offspring, the expression of these genes in male offspring did not differ significantly between the DHEA and control groups (Fig. 5B).

\section{Discussion}

DHEA is a metabolic intermediate in the biosynthesis of androgen and is one of the many drugs, including testosterone and letrozole, that are used for animal models of PCOS by prenatal or prepubertal exposure (Luchetti et al. 2004, Manneras et al. 2007). In our study, PCOS was induced by the administration of DHEA ( $6 \mathrm{mg} / 100 \mathrm{~g}$ body weight) for 20 consecutive days in prepubertal BALB/c mice (Sander et al. 2006, Abramovich et al. 2012, Zhang et al. 2013). This dose of DHEA ensures a hyperandrogenized status equivalent to that found in women with PCOS (Lee et al. 1991, Luchetti et al. 2004, Solano et al. 2006). An increase in fat and stromal tissue is observed in ovaries of prepubertal mice from DHEA-treated mice (Luchetti et al. 2004). Furthermore, the ovarian cortex of treated mice has more cysts, which show a thin layer of theca cells and compacted granulosa cells with the absence of a vascularized theca interna. Decreased insulin sensitivity, increased ovarian oxidative stress, altered serum estradiol and progesterone levels, and ovarian immunosuppressor prostaglandin E were also apparent in prepubertal hyperandrogenism after DHEA treatment (Luchetti et al. 2004, Elia et al. 2006). Characteristics of DHEA-treated mice, especially hyperandrogenism, are similar to those exhibited by women with PCOS. Therefore, we chose this PCOS mouse model to assess the growth and metabolic characteristics of PCOS offspring.

We examined the stage of cyclicity, ovarian morphology, hormone levels and changes in metabolism and fertility in mice after 20 consecutive days of DHEA injection. The results showed that all mice from the DHEA group, whose ovaries were markedly swollen and had multiple follicular cysts, were completely acyclic and remained in constant estrous. Levels of testosterone, TG and $\mathrm{CHO}$ were significantly increased, and the weight gain and fat mass were significantly greater than those in the control group, as noted in our previous study (Huang et al. 2015).

A number of animal studies have shown that excessive intrauterine androgen exposure results in many problems in offspring, such as excessive weight gain, visceral and subcutaneous fat accumulation, increased fat cell volume, impaired glucose tolerance, decreased insulin sensitivity and lipid metabolism disorders (Demissie et al. 2008, Roland et al. 2010, Yan et al. 2013). PCOS mothers have a significantly higher prevalence of birthing both small- and large-for-gestational-age newborns, and birth length for the latter is significantly greater than that of controls (Sir-Petermann et al. 2005). Assessment of prepubertal daughters of patients with PCOS revealed significantly greater bone age and basal height compared with prepubertal girls in the control group, although body mass index did not differ significantly between the groups (Battaglia et al. 2002). However, the study included only 15 prepubertal offspring of patients with PCOS and 10 control prepubertal girls, and longerterm follow-up studies concerning offspring of PCOS women are rare. A rat model in which PCOS was induced by prenatal exposure to testosterone revealed no significant differences in body weight of offspring at birth and postnatal day 15 , but when compared with controls at 30, 45 and 60 days of age and in adulthood, the body weight of PCOS rat offspring was significantly greater (Noroozzadeh et al. 2015). However, none of the studies mentioned previously distinguished the female and male offspring. We found that, although the body weight of female offspring of DHEA mice was significantly greater than that of the control group from postnatal week 1 into adulthood, the body weight of the male offspring of the DHEA group in the period of 1-4 weeks after birth was also significantly greater; however, there was no significant difference from weeks $5-12$. The reason for this might be that, before puberty, the body weight of offspring was influenced by PCOS mothers as a consequence of parenting factors related to the physical and pathological state of this syndrome. During adolescence and adulthood, however, female body weight is more easily affected by ovarian hormones. Ovarian physiopathological characteristics of female offspring might be inherited from the PCOS mother, and resulting in greater body weight gain. On the other hand, because there was an inverse relation between the average body weight and litter size (Reddy \& Reddy, 1982), the significantly smaller litter size of PCOS dams may have the consequence of increased mean body weight of offspring simply due to increased access to maternal resources, both in utero and postnatally. It is hard for us to completely exclude the maternal resource factor. This could be a confounding factor, and it is a limitation of our study.

In this study, mild glucolipid metabolism disorders existed in the female offspring in the DHEA group, 
such as increased body fat and serum TG and impaired glucose tolerance. Decreased energy consumption might be one of the causative factors. The phenomenon may also be due to epigenetic and pathophysiological changes in metabolic tissue resulting from the female fetus's exposure to elevated testosterone level (Abbott et al. 2010). Studies with rhesus monkeys showed that androgen treatment in different gestational periods yields different outcomes. Excess androgen in early gestation programs both hyperinsulinemia from adiposity-dependent insulin resistance and preferential accumulation of visceral adiposity, whereas androgen excess later in gestation decreases insulin sensitivity and increases non-visceral abdominal fat, although insulin secretion is unaffected (Bruns et al. 2007, Abbott et al. 2010). Prenatal androgenization of female rhesus monkeys may modify DNA methylation patterns in both infant and adult visceral adipose tissues (Xu et al. 2011), suggesting that changes in offspring metabolism may be related to alterations in DNA methylation or other epigenetic modifications.

Because of the increased catabolism of fat associated with insulin resistance, however, the consequent excessive free fatty acids in the circulation are transported to the liver. When oxygenolysis in liver mitochondria is insufficient to catabolize the excess free fatty acids, the remaining free fatty acids accumulate in the liver, resulting in an increase in TG level (Tolman et al. 2004). Pyruvate dehydrogenase kinase (PDK) 4 is a member of enzymes that inhibit the activity of the pyruvate dehydrogenase complex, and PDK links the glycolytic degradation of glucose to the tricarboxylic acid cycle through the rate-limiting and physiologically irreversible oxidative decarboxylation of pyruvate (Sugden \& Holness 2006). PDK4 is primarily expressed in liver, heart and skeletal muscle. A high-fat diet significantly increases the level of PDK4 in skeletal muscle and cardiac muscle of mice. In addition, diabetes, hunger or fatty acids converted by sugars as energy source also upregulate PDK4 expression significantly (Feige \& Auwerx 2007, Connaughton et al. 2010, RinnankoskiTuikka et al. 2012, Zhang et al. 2012). In our study, the increased expression of Pdk4 in the DHEA group inhibited the activity of pyruvate dehydrogenase, which may be one of the reasons for the observed decrease in insulin sensitivity.

Peroxisome proliferator-activated receptor $\gamma(\operatorname{PPAR} \gamma)$, a member of the nuclear hormone receptor superfamily, is a class of ligand-activated transcription factors that play a key role in glucose homeostasis and maintaining lipid metabolism. It was traditionally believed that one subtype of PPAR $\gamma$ is expressed in adipose tissue, in which it regulates preadipocyte differentiation and promotes adipocyte maturation (He et al. 2003). However, some studies have shown that PPAR $\gamma$ also plays a functional role in liver, muscle and other tissues (Vidal-Puig et al. 1996, Norris et al. 2003). Activated PPAR the sensitivity of peripheral tissues to insulin, decreases insulin resistance and lowers blood glucose (Lazar 2005, Badman et al. 2007, King et al. 2007) through signaling pathways of acyl-CoA thioesterases and fibroblast growth factor 21 (FGF21) (Lazar 2005, Badman et al. 2007, King et al. 2007). These thioesterases comprise a class of enzymes that catalyze the conversion acylcoenzyme A to free fatty acids via hydrolysis, which is regulated by PPAR $\gamma$ and play an important role in fatty acid synthesis and degradation (Hunt \& Alexson 2002). FGF21, which was recently discovered, is a potent regulator of glucose uptake in adipocytes, regulating both glucose and lipid metabolism through fatty acid oxidation in the liver (Kharitonenkov et al. 2005). Overexpression of FGF21 in transgenic mice prohibits diet-induced obesity. FGF21 treatment can reduce body weight, blood glucose and blood lipids and reverse hepatic steatosis in diabetic mice (Kharitonenkov et al. 2005, Xu et al. 2009). The expression of Ppary, Acot1, Acot2 and Fgf2 1 were increased in the liver of PCOS offspring mice, which may be related to compensatory adjustment for confrontation of dyslipidemia or protein resistance of the above-mentioned molecules. Similarly, one study showed that, when the body contained higher fatty acids, as a result of diabetes or a high-fat diet, the expression of Acot 1 and Acot 2 was upregulated in liver, thereby promoting the catabolism of fatty acids (Yamada et al. 2003). Human serum FGF21 levels also correlate positively with body mass index, as evidenced by the significantly increased level of serum FGF21 in obese patients (Zhang et al. 2008, Dushay et al. 2010). Overall, Ppary, Acots, Fgf2 1 and Pdk4 all play important roles in regulating glucose and lipid metabolism, and the regulatory mechanisms are complex because the expression of these four genes is affected by many factors such as hunger and diet. Changes in the expression of these genes may be closely associated with the observed glycolipid metabolism disorder in offspring of DHEA-induced mice, and the increased levels of PPAR $\gamma$ and FGF21 in the liver of PCOS offspring may be a compensatory mechanism that maintains normal glucose and lipid metabolism.

The gene, CYP17A1, encodes an enzyme of the cytochrome P450 superfamily, and it plays a role in cortisol production in humans and animals (Lima et al. 2015). In humans, CYP17A1 is responsible for the synthesis of P450c17, which is a key enzyme in the steroidogenic pathway for the metabolic conversion of progesterones to adrenal androgens and their subsequent conversion to testosterone (Fan et al. 2009, Kosaka et al. 2014). Androgens serve as precursors to estrogens, so normal estrogen signaling also depends on CYP17A1, which plays a very important role in many other physiological and pathological processes such as vascular endothelium repair and lipid metabolism. Moreover, CYP17A1 is also involved in glucose metabolism and insulin-related signal transduction 
pathways (Dai et al. 2015). Studies have shown increased expression of CYP17 genes in theca cells derived from PCOS women and an endogenous hyperandrogenism rat model of PCOS (Wood et al. 2003, Li et al. 2013). However, lipopolysaccharide levels in ovarian follicular fluid of dairy cows influence CYP17 expression in theca cells (Magata et al. 2014). In follicles with a high level of lipopolysaccharides, CYP17 expression was lower (Magata et al. 2014). This study showed that Cyp17a1 mRNA level was significantly decreased in liver tissue of DHEA female offspring, which may be related to body weight gain, increased body fat and TG content or to impaired glucose tolerance. In conclusion, we found that the average litter size was significantly smaller in the DHEA group, and the female offspring in the DHEA group showed sustained greater body weight, increased body fat and TG content in serum and liver; decreased energy expenditure and oxygen consumption; and impaired glucose tolerance. In liver tissue of female offspring of the DHEA group, the glucolipid metabolism-related genes such as Ppary, Acot1/2, Fgf21, Pdk4 and Inhbb were upregulated, whereas Cyp17a1 was significantly downregulated.

\section{Supplementary data}

This is linked to the online version of the paper at http://dx.doi. org/10.1530/REP-16-0081.

\section{Declaration of interest}

The authors declare that there is no conflict of interest that could be perceived as prejudicing the impartiality of the research reported.

\section{Funding}

This work was supported in part by grants from the Ministry of Science and Technology of China (973 program; 2014CB943203), 'Reproductive health and major birth defects prevention and control research' Key Special Fund (2016YFC1000601), the National Natural Science Foundation General Program (81300543, 81571400 and 31501201), the Beijing Nova Program (xxjh2015011), the Specialized Research Fund for the Doctoral Program of Higher Education (20120001130008) and special projects of the 2015 Science and Technology Innovation Base Cultivation and Development (Z151100001615023).

\section{Author contribution statement}

The principal investigators Y Zhao, R Li, Y Yu and J Qiao take primary responsibility for the paper and contributed to the conception, design and coordination of the research. Y Huang and J-M Gao performed the experiment and data analysis. $\mathrm{C}-\mathrm{M}$ Zhang and $\mathrm{H}-\mathrm{C}$ Zhao contributed to the acquisition of reagents/materials/analysis tools. Y Huang and J-M Gao contributed to writing the manuscript. $Y$ Zhao, $R \mathrm{Li}$ and $\mathrm{Y} Y \mathrm{Uu}$ contributed to the revision of the article, and the final version was approved by all the authors.

\section{References}

Abbott DH, Bruns CR, Barnett DK, Dunaif A, Goodfriend TL, Dumesic DA \& Tarantal AF 2010 Experimentally induced gestational androgen excess disrupts glucoregulation in rhesus monkey dams and their female offspring. American Journal of Physiology Endocrinology and Metabolism 299 E741-E751. (doi:10.1152/ajpendo.00058.2010)

Abramovich D, Irusta G, Bas D, Cataldi NI, Parborell F \& Tesone M 2012 Angiopoietins/TIE2 system and VEGF are involved in ovarian function in a DHEA rat model of polycystic ovary syndrome. Endocrinology 153 3446-3456. (doi:10.1210/en.2012-1105)

Anderson H, Fogel N, Grebe SK, Singh RJ, Taylor RL \& Dunaif A 2010 Infants of women with polycystic ovary syndrome have lower cord blood androstenedione and estradiol levels. Journal of Clinical Endocrinology and Metabolism 95 2180-2186. (doi:10.1210/jc.2009-2651)

Badman MK, Pissios P, Kennedy AR, Koukos G, Flier JS \& Maratos-Flier E 2007 Hepatic fibroblast growth factor 21 is regulated by PPARalpha and is a key mediator of hepatic lipid metabolism in ketotic states. Cell Metabolism 5 426-437. (doi:10.1016/j.cmet.2007.05.002)

Battaglia C, Regnani G, Mancini F, lughetti L, Flamigni C \& Venturoli S 2002 Polycystic ovaries in childhood: a common finding in daughters of PCOS patients. A pilot study. Human Reproduction 17 771-776. (doi:10.1093/humrep/17.3.771)

Boomsma CM, Eijkemans MJ, Hughes EG, Visser GH, Fauser BC \& Macklon NS 2006 A meta-analysis of pregnancy outcomes in women with polycystic ovary syndrome. Human Reproduction Update 12 673-683. (doi:10.1093/humupd/dml036)

Bruns CM, Baum ST, Colman RJ, Dumesic DA, Eisner JR, Jensen MD, Whigham LD \& Abbott DH 2007 Prenatal androgen excess negatively impacts body fat distribution in a nonhuman primate model of polycystic ovary syndrome. International Journal of Obesity 31 1579-1585. (doi:10.1038/sj.ijo.0803638)

Carmina E, Koyama T, Chang L, Stanczyk FZ \& Lobo RA 1992 Does ethnicity influence the prevalence of adrenal hyperandrogenism and insulin resistance in polycystic-ovary-syndrome. American Journal of Obstetrics and Gynecology 167 1807-1812. (doi:10.1016/00029378(92)91779-A)

Connaughton S, Chowdhury F, Attia RR, Song S, Zhang Y, Elam MB, Cook GA \& Park EA 2010 Regulation of pyruvate dehydrogenase kinase isoform 4 (PDK4) gene expression by glucocorticoids and insulin. Molecular and Cellular Endocrinology 315 159-167. (doi:10.1016/ j.mce.2009.08.011)

Crisosto N, Codner E, Maliqueo M, Echiburu B, Sanchez F, Cassorla F \& Sir-Petermann T 2007 Anti-Mullerian hormone levels in peripubertal daughters of women with polycystic ovary syndrome. Journal of Clinical Endocrinology and Metabolism 92 2739-2743. (doi:10.1210/jc.20070267)

Dai CF, Xie X, Yang YN, Li XM, Zheng YY, Fu ZY, Liu F, Chen BD, Gai MT \& Ma YT 2015 Relationship between CYP17A1 genetic polymorphism and coronary artery disease in a Chinese Han population. Lipids in Health and Disease 14 16. (doi:10.1186/s12944-015-0007-4)

Demissie M, Lazic M, Foecking EM, Aird F, Dunaif A \& Levine JE 2008 Transient prenatal androgen exposure produces metabolic syndrome in adult female rats. American Journal of Physiology Endocrinology and Metabolism 295 E262-E268. (doi:10.1152/ajpendo.90208.2008)

Dushay J, Chui PC, Gopalakrishnan GS, Varela-Rey M, Crawley M, Fisher FM, Badman MK, Martinez-Chantar ML \& Maratos-Flier E 2010 Increased fibroblast growth factor 21 in obesity and nonalcoholic fatty liver disease. Gastroenterology 139 456-463. (doi:10.1053/ j.gastro.2010.04.054)

Elia E, Sander V, Luchetti CG, Solano ME, Di Girolamo G, Gonzalez C \& Motta AB 2006 The mechanisms involved in the action of metformin in regulating ovarian function in hyperandrogenized mice. Molecular Human Reproduction 12 475-481. (doi:10.1093/molehr/gal057)

Fan YM, Raitakari OT, Kahonen M, Hutri-Kahonen N, Juonala M, Marniemi J, Viikari J \& Lehtimaki T 2009 Hepatic lipase promoter C-480T polymorphism is associated with serum lipids levels, but 
not subclinical atherosclerosis: the Cardiovascular Risk in Young Finns Study. Clinical Genetics 76 46-53. (doi:10.1111/j.13990004.2009.01180.x)

Feige JN \& Auwerx J 2007 Transcriptional coregulators in the control of energy homeostasis. Trends in Cell Biology 17 292-301. (doi:10.1016/ j.tcb.2007.04.001)

He W, Barak Y, Hevener A, Olson P, Liao D, Le J, Nelson M, Ong E, Olefsky JM \& Evans RM 2003 Adipose-specific peroxisome proliferatoractivated receptor gamma knockout causes insulin resistance in fat and liver but not in muscle. PNAS 100 15712-15717. (doi:10.1073/ pnas.2536828100)

Huang Y, Yu Y, Gao J, Li R, Zhang C, Zhao H, Zhao Y \& Qiao J 2015 Impaired oocyte quality induced by dehydroepiandrosterone is partially rescued by metformin treatment. PLOS ONE 10 e0122370. (doi:10.1371/ journal.pone.0122370)

Hunt MC \& Alexson SE 2002 The role Acyl-CoA thioesterases play in mediating intracellular lipid metabolism. Progress in Lipid Research $\mathbf{4 1}$ 99-130. (doi:10.1016/S0163-7827(01)00017-0)

Kahsar-Miller MD, Nixon C, Boots LR, Go RC \& Azziz R 2001 Prevalence of polycystic ovary syndrome (PCOS) in first-degree relatives of patients with PCOS. Fertility and Sterility 75 53-58. (doi:10.1016/S00150282(00)01662-9)

Kharitonenkov A, Shiyanova TL, Koester A, Ford AM, Micanovic R, Galbreath EJ, Sandusky GE, Hammond LJ, Moyers JS, Owens RA et al. 2005 FGF-21 as a novel metabolic regulator. Journal of Clinical Investigation 115 1627-1635. (doi:10.1172/JCI23606)

King KL, Young ME, Kerner J, Huang $\mathrm{H}$, O'Shea KM, Alexson SE, Hoppel CL \& Stanley WC 2007 Diabetes or peroxisome proliferatoractivated receptor alpha agonist increases mitochondrial thioesterase I activity in heart. Journal of Lipid Research 48 1511-1517. (doi:10.1194/ jlr.M600364-JLR200)

Kosaka T, Miyajima A, Yasumizu Y, Miyazaki Y, Kikuchi E \& Oya M 2014 Limited in vitro efficacy of CYP17A1 inhibition on human castration resistant prostate cancer. Steroids 92 39-44. (doi:10.1016/ j.steroids.2014.07.017)

Lazar MA 2005 PPAR gamma, 10 years later. Biochimie 87 9-13. (doi:10.1016/j.biochi.2004.10.021)

Lee MT, Anderson E \& Lee GY 1991 Changes in ovarian morphology and serum hormones in the rat after treatment with dehydroepiandrosterone. Anatomical Record 231 185-192. (doi:10.1002/ar.1092310206)

Lee CH, Olson P \& Evans RM 2003 Minireview: lipid metabolism, metabolic diseases, and peroxisome proliferator-activated receptors. Endocrinology 144 2201-2207. (doi:10.1210/en.2003-0288)

Legro RS, Driscoll D, Strauss JF 3rd, Fox J \& Dunaif A 1998 Evidence for a genetic basis for hyperandrogenemia in polycystic ovary syndrome. PNAS 95 14956-14960. (doi:10.1073/pnas.95.25.14956)

Li H, Chen Y, Yan LY \& Qiao J 2013 Increased expression of P450scc and CYP17 in development of endogenous hyperandrogenism in a rat model of PCOS. Endocrine 43 184-190. (doi:10.1007/s12020-012-9739-3)

Lima GN, Maganhin CC, Simoes RS, Baracat MC, Sasso GR, Fuchs LF, Simoes Mde J, Baracat EC \& Soares Junior JM 2015 Steroidogenesisrelated gene expression in the rat ovary exposed to melatonin supplementation. Clinics 70 144-151. (doi:10.6061/clinics/2015(02)12)

Luchetti CG, Solano ME, Sander V, Arcos ML, Gonzalez C, Di Girolamo G, Chiocchio S, Cremaschi G \& Motta AB 2004 Effects of dehydroepiandrosterone on ovarian cystogenesis and immune function. Journal of Reproductive Immunology 64 59-74. (doi:10.1016/ j.jri.2004.04.002)

Magata F, Horiuchi M, Echizenya R, Miura R, Chiba S, Matsui M, Miyamoto A, Kobayashi Y \& Shimizu T 2014 Lipopolysaccharide in ovarian follicular fluid influences the steroid production in large follicles of dairy cows. Animal Reproduction Sciences 144 6-13. (doi:10.1016/ j.anireprosci.2013.11.005)

Manneras L, Cajander S, Holmang A, Seleskovic Z, Lystig T, Lonn M \& Stener-Victorin E 2007 A new rat model exhibiting both ovarian and metabolic characteristics of polycystic ovary syndrome. Endocrinology 148 3781-3791. (doi:10.1210/en.2007-0168)

Moran C, Knochenhauer E, Boots LR \& Azziz R 1999 Adrenal androgen excess in hyperandrogenism: relation to age and body mass. Fertility and Sterility 71 671-674. (doi:10.1016/S0015-0282(98)00536-6)
Nakamura MT, Yudell BE \& Loor JJ 2014 Regulation of energy metabolism by long-chain fatty acids. Progress in Lipid Research 53 124-144. (doi:10.1016/j.plipres.2013.12.001)

Noroozzadeh M, Ramezani Tehrani F, Sedaghat K, Godini A \& Azizi F 2015 The impact of prenatal exposure to a single dose of testosterone on insulin resistance, glucose tolerance and lipid profile of female rat's offspring in adulthood. Journal of Endocrinological Investigation $\mathbf{3 8}$ 489-495. (doi:10.1007/s40618-014-0198-y)

Norris AW, Chen L, Fisher SJ, Szanto I, Ristow M, Jozsi AC, Hirshman MF, Rosen ED, Goodyear LJ, Gonzalez FJ et al. 2003 Muscle-specific PPARgamma-deficient mice develop increased adiposity and insulin resistance but respond to thiazolidinediones. Journal of Clinical Investigation 112 608-618. (doi:10.1172/JCl17305)

Rakhshandehroo M, Knoch B, Muller M \& Kersten S 2010 Peroxisome proliferator-activated receptor alpha target genes. PPAR Research 2010 1-17. (doi:10.1155/2010/612089)

Reddy EM \& Reddy RR 1982 Effect of litter size and parity on weight gains of albino mice litters. Journal of Dairy Science 65 281-283. (doi:10.3168/jds.S0022-0302(82)82189-9)

Rinnankoski-Tuikka R, Silvennoinen M, Torvinen S, Hulmi JJ, Lehti M, Kivela R, Reunanen H \& Kainulainen H 2012 Effects of high-fat diet and physical activity on pyruvate dehydrogenase kinase- 4 in mouse skeletal muscle. Nutrition and Metabolism 9 53. (doi:10.1186/17437075-9-53)

Roland AV, Nunemaker CS, Keller SR \& Moenter SM 2010 Prenatal androgen exposure programs metabolic dysfunction in female mice. Journal of Endocrinology 207 213-223. (doi:10.1677/JOE-10-0217)

Sander V, Luchetti CG, Solano ME, Elia E, Di Girolamo G, Gonzalez C \& Motta AB 2006 Role of the N, N'-dimethylbiguanide metformin in the treatment of female prepuberal BALB/C mice hyperandrogenized with dehydroepiandrosterone. Reproduction 131 591-602. (doi:10.1530/ rep.1.00941)

Sir-Petermann T, Hitchsfeld C, Maliqueo M, Codner E, Echiburu B, Gazitua R, Recabarren S \& Cassorla F 2005 Birth weight in offspring of mothers with polycystic ovarian syndrome. Human Reproduction $\mathbf{2 0}$ 2122-2126. (doi:10.1093/humrep/dei009)

Sir-Petermann T, Codner E, Maliqueo M, Echiburu B, Hitschfeld C, Crisosto N, Perez-Bravo F, Recabarren SE \& Cassorla F 2006 Increased anti-Mullerian hormone serum concentrations in prepubertal daughters of women with polycystic ovary syndrome. Journal of Clinical Endocrinology and Metabolism 91 3105-3109. (doi:10.1210/jc.20052693)

Sir-Petermann T, Maliqueo M, Codner E, Echiburu B, Crisosto N, Perez V, Perez-Bravo F \& Cassorla F 2007 Early metabolic derangements in daughters of women with polycystic ovary syndrome. Journal of Clinical Endocrinology and Metabolism 92 4637-4642. (doi:10.1210/jc.20071036)

Sir-Petermann T, Codner E, Perez V, Echiburu B, Maliqueo M, Ladron de Guevara A, Preisler J, Crisosto N, Sanchez F, Cassorla F et al. 2009 Metabolic and reproductive features before and during puberty in daughters of women with polycystic ovary syndrome. Journal of Clinical Endocrinology and Metabolism 94 1923-1930. (doi:10.1210/jc.20082836)

Smith SA 2002 Peroxisome proliferator-activated receptors and the regulation of mammalian lipid metabolism. Biochemical Society Transactions 30 1086-1090. (doi:10.1042/bst0301086)

Solano ME, Elia E, Luchetti CG, Sander V, Di Girolamo G, Gonzalez C \& Motta AB 2006 Metformin prevents embryonic resorption induced by hyperandrogenisation with dehydroepiandrosterone in mice. Reproduction, Fertility and Development 18 533-544. (doi:10.1071/ RD05099)

Sugden MC \& Holness MJ 2006 Mechanisms underlying regulation of the expression and activities of the mammalian pyruvate dehydrogenase kinases. Archives of Physiology and Biochemistry 112 139-149. (doi:10.1080/13813450600935263)

Tolman KG, Fonseca V, Tan MH \& Dalpiaz A 2004 Narrative review: hepatobiliary disease in type 2 diabetes mellitus. Annals of Internal Medicine 141 946-956. (doi:10.7326/0003-4819-141-12-20041221000011)

Vidal-Puig A, Jimenez-Linan M, Lowell BB, Hamann A, Hu E, Spiegelman B, Flier JS \& Moller DE 1996 Regulation of PPAR gamma gene expression 
by nutrition and obesity in rodents. Journal of Clinical Investigation $\mathbf{9 7}$ 2553-2561. (doi:10.1172/JCI118703)

Wood JR, Nelson VL, Ho C, Jansen E, Wang CY, Urbanek M, McAllister JM, Mosselman S \& Strauss JF 3rd 2003 The molecular phenotype of polycystic ovary syndrome (PCOS) theca cells and new candidate PCOS genes defined by microarray analysis. Journal of Biological Chemistry 278 26380-26390. (doi:10.1074/jbc.M300688200)

Xu J, Lloyd DJ, Hale C, Stanislaus S, Chen M, Sivits G, Vonderfecht S, Hecht R, Li YS, Lindberg RA et al. 2009 Fibroblast growth factor 21 reverses hepatic steatosis, increases energy expenditure, and improves insulin sensitivity in diet-induced obese mice. Diabetes 58 250-259. (doi:10.2337/db08-0392)

Xu N, Kwon S, Abbott DH, Geller DH, Dumesic DA, Azziz R, Guo X \& Goodarzi MO 2011 Epigenetic mechanism underlying the development of polycystic ovary syndrome (PCOS)-like phenotypes in prenatally androgenized rhesus monkeys. PLOS ONE 6 e27286. (doi:10.1371/ journal.pone.0027286)

Yamada J, Kuramochi Y, Takoda Y, Takagi M \& Suga T 2003 Hepatic induction of mitochondrial and cytosolic acyl-coenzyme a hydrolases/ thioesterases in rats under conditions of diabetes and fasting. Metabolism 52 1527-1529. (doi:10.1016/j.metabol.2003.07.001)

Yan X, Dai X, Wang J, Zhao N, Cui Y \& Liu J 2013 Prenatal androgen excess programs metabolic derangements in pubertal female rats. Journal of Endocrinology 217 119-129. (doi:10.1530/JOE-12-0577)
Yoon M 2009 The role of PPARalpha in lipid metabolism and obesity: focusing on the effects of estrogen on PPARalpha actions. Pharmacological Research 60 151-159. (doi:10.1016/j.phrs.2009.02.004)

Zhang X, Yeung DC, Karpisek M, Stejskal D, Zhou ZG, Liu F, Wong RL, Chow WS, Tso AW, Lam KS et al. 2008 Serum FGF21 levels are increased in obesity and are independently associated with the metabolic syndrome in humans. Diabetes 57 1246-1253. (doi:10.2337/ db07-1476)

Zhang L, Mori J, Wagg C \& Lopaschuk GD 2012 Activating cardiac E2F1 induces up-regulation of pyruvate dehydrogenase kinase 4 in mice on a short term of high fat feeding. FEBS Letters $\mathbf{5 8 6}$ 996-1003. (doi:10.1016/ j.febslet.2012.02.027)

Zhang X, Zhang C, Shen S, Xia Y, Yi L, Gao Q \& Wang Y 2013 Dehydroepiandrosterone induces ovarian and uterine hyperfibrosis in female rats. Human Reproduction 28 3074-3085. (doi:10.1093/ humrep/det341)

Received 15 February 2016

First decision 23 March 2016

Revised manuscript received 9 September 2016

Accepted 19 September 2016 